be used, fifteen miles in all. The whole fence was finished within a year from the start.

Constant vigilance is necessary to keep the fence in daily repair. Elephant on their customary journeys have smashed through the structure time and again; but fortunately elephant do not carry rinderpest. A human cordon ran the length of the fence : pickets of native African guards, patrolling and linking up each day so that nothing could get through without detection, all under two white officers' supervision. At the eastern end of the fence Nyasaland linked up and carried the human cordon down to the shores of Lake Nyasa, thus completing the great barrier between the two lakes. The game in the fence zone is gradually being pushed back on either side, and in time the danger of contact between north and south should pass away. But the fence itself has proved so valuable in controlling the position that attempts are now being made to prolong its life indefinitely by trenching (the best security against wild pigs) and planting thorns and sharp-spiked sisals which will discourage any buffalo or soft-skinned game from approaching even if they do escape the vigilance of the hunters.

\section{New Synthetic Rubber}

A NEW specialty rubber known as 'Paracon' has been developed by the Bell Laboratories, which looks and feels like ordinary rubber and resembles it fairly closely in mechanical properties (Bell Lab. Rec., 20, No. 9 ; May 1943). It has a high resistance to damage by oil or petrol and is better than natural rubber in resistance to heat, light and oxidation, although inferior to it in resistance to steam, alkalis and acids. 'Paracon' can be worked with ordinary rubber machinery. In its raw state it is highly plastic and unusually well adapted to moulding into intricate shapes and to use in producing rubberized fabrics. 'Paracon' does not compete with other synthetic rubbers for its basic raw materials since the chemical intermediates required for its production are derived by other trains of chemical processes. For its synthesis it uses materials derived from agricultural products and coal products, or from coal and petroleum sources, and in each case by a variety of different chemical processes. The equipment for manufacturing 'Paracon' differs from that required for synthetic rubber production and, consequently, the new material can add to the present supply of rubber substitutes without interfering with the production of those already under way. The synthesis of 'Paracon' was accomplished by Drs. C. S. Fuller and B. S. Biggs of the Bell Laboratories and their associates.

\section{Public Health in Peru}

THE February issue of the Boletin de la Oficina Sanataria Panamericana contains an article on public health in Peru by Dr. Manuel Prado, president of the Republic, who states that during 194 I-42 more attention has been given to it by the Government than ever before. Owing to the general census of 1940 much more accurate data have been made available. The birth-rate, for example, is now found to be rising in many of the provincial capitals, while the death-rate remains unchanged in most of the villages. Considerable attention has been given to children. In addition to the Children's Hospital, which receives children not only from Lima but also from neighbouring villages and towns, there is a National Children's Institute which has made possible the creation in various cities of sections of maternal aid, social hygiene, maternal education and food dispensaries. An intense campaign has been carried out against disease, especially tuberculosis and malaria. Clinies for tuberculosis have been established in three cities and others will soon be formed. A portable X-ray apparatus has been provided for rural communities as well as other means for the diagnosis and treatment of this disease. The Rockefeller Foundation is now collaborating with the Peruvian Ministry of Health in an effort to free the valleys of the coast from malaria. Preventive measures are reducing the foci of other diseases, particularly venereal diseases. First-aid services are assuming greater importance not only for minor accidents but also for major catastrophes. The value of sanitary engineering has recently been proved by its control over bathing establishments and markets, and over food, especially milk.

\section{Narcotic Drug Addicts}

IN Supplement No. 170 of Public Health Reports Dr. Michael J. Pescor, assistant surgeon, United States Public Health Service, records a follow-up study of 4,766 narcotic drug addicts who had been discharged from the United States Public Health Service Hospital at Lexington, Kentucky, during January 1, 1936-December 31, 1940. The results were as follows: The present state could not be determined in $39 \cdot 6$ per cent of the cases; $7 \cdot 0$ per cent died after discharge; 39.9 per cent returned to the use of drugs and 13.5 per cent were still abstinent. Excluding the dead and the unknown, $74 \cdot 7$ per cent had relapsed and $25 \cdot 3$ per cent were still abstinent. 57 per cent of the patients gave no history of subsequent admission to any institution; 19.9 per cent were re-admitted to other institutions, 16.0 per cent returned to the Lexington Hospital only and $7 \cdot 1$ per cent were re-admitted both to the Lexington Hospital and other institutions. According to Pescor the theoretically ideal patient, that is the one with the best prospects for a permanent cure, is the one who stays in the hospital for 2-5 months, after which he is discharged on parole for a period of supervision of $2-5$ months, during which he would have home employment.

\section{Poliomyelitis in the Argentine}

According to the Journal of the American Medical Association of February 6, the number of cases of acute poliomyelitis in the Argentine since last Novem. ber was greater than in previous epidemics and the course of the disease has been similar to that of the 1936 epidemics. About four hundred cases were reported in two months in the epidemic area, in which more than seven hundred cases were observed during the whole epidemic period of five months in 1936. Separate wards and six hundred beds in various hospitals have been reserved for cases of the disease. Good results have recently been reported from the use of tetanus toxin.

\section{Prevention of Blindness}

THE Department of Health for Scotland has recently issued a circular containing the following advice to local authorities on the prevention of blindness : (1) A wider use should be made of special schools and classes for children whose eyesight is defective, arrangements being made with neighbouring authorities when necessary. (2) There should be a closer connexion with industrial medical services to 